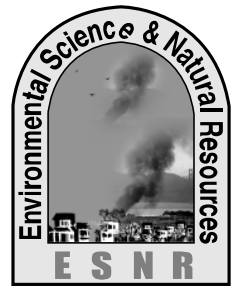

J. Environ. Sci. \& Natural Resources, 6(2): 13 -18, 2013

ISSN 1999-7361

\title{
Farmers' Perception of Environmental Degradation Due to Use of Pesticides
}

\author{
S. Akter, M. A. Miah, ${ }^{1}$ M. Z. Rhaman, M. S. Hossen and M. A. Baten \\ Department of Environmental Science, ${ }^{1}$ Department of Agricultural Extension Education, Bangladesh \\ Agricultural University, Mymensingh.
}

\begin{abstract}
The study was conducted mainly to have an understanding about the farmers' perception of environmental degradation due to use of pesticides. Data for the study were collected by personal interviewing from 69 randomly selected farmers of Kabaria kanda village of sadar upazila of Mymensingh district during the period of 01 November to 15 November, 2012. Pearson's product moment correlation co-efficient were computed to examine the relationship between the concerned variables. Perception on environmental degradation was reflected more in the young (30.4 percent) to middle age (42 percent) group compared to old age group. Majority (72.5 percent) of the farmers in the study area were found to have no organizational participation. The highest proportion (73.9 percent) of the respondents fell in the moderate knowledge category while none fell in less knowledge and 26.1 percent in the high knowledge category respectively. Only 1.4 percent of the farmers had moderately perception on environmental knowledge as compared to 98.6 percent favorable perception. Out of eight independent variables, five of them, i.e. years of schooling, farm size, annual family income, media exposure and knowledge on the use of agro-chemicals had positive relationships with their perception of environmental degradation due use of pesticides. Only three independent variable i.e. age, household size and organizational participation had no relationship with their perception of environmental degradation due use of pesticides.
\end{abstract}

Keyword: Environment Degradation, Farmers, Pesticides

\section{Introduction}

Environment is considered as a composite term for the conditions in which organisms live. It includes both biotic and abiotic substance, energy and force e.g. temperature, light, water, air, soil and other organisms. It is a totality of all social, biological, physical and chemical factors individually as well as collectively that compose the nature and manmade surroundings. In recent years, the issue of environmental degradation has caused great concern both nationally and internationally. Agriculture and environment interact in such a way that agricultural growth depends on the proper functioning of the environment process, the same way that environmental soundness depends upon agriculture (Conway, 1990). Thus, agriculture simultaneously because a 'victim' and a 'cause' of ecological destruction (Hossain, et al., 1994). Our environmental balance is deteriorating rapidly because of a number of causes such as haphazard use of agrochemicals in farming, deforestation and various green house gases (GHGs) like chlorofluorocarbon (CFC), carbon dioxide $\left(\mathrm{CO}_{2}\right)$, methane $\left(\mathrm{CH}_{4}\right)$, nitrous oxide $\left(\mathrm{N}_{2} \mathrm{O}\right)$, ozone $\left(\mathrm{O}_{3}\right)$ etc. These gases are accessible to high energy solar radiation having short wave length but absorb long wave terrestrial radiation thus trapping heat in the lower atmosphere.

Many problems, adverse effects or hazardous action of fertilizer in soils, crops, human health, air, water and other environments. Some of the major problems mentioned were decreased the organic matter and iodine content in soils, soil hardening, increased soil acidity or alkalinity, caused diseases to certain fish species, decreased population of soil organisms including earthworms and reduced soil fertility, changed the taste and quality of some fruits, vegetables, polluted the surface as well as ground water etc ( Satter, 1994). Indiscriminate use of pesticides also affect in the aquatic organisms. Men heavily depend on fishes and aquatic plants for their lives. It is very harmful for human health (Sarker, 1993). Use of improper does of pesticides makes the pest resistant requiring further stronger doses of chemicals. Consequently, a huge amount of residual chemicals has been causing drastic lethal effects on the consumers. Strong residual effects of DDT, Eldrin and Dieldrin also cause health hazards to human and animals and kill other beneficial insects.

Environment and agriculture are closely interlinked. We depend on the environment, on the resources of land, water, sunlight, and biological organisms, for expansion of agricultural production. It has been found in different countries of the world that in addition to beneficial effect, the improved agricultural practices have tremendous relevance to environmental pollution and Bangladesh is not an exception to this (Sattar, 1994). The improved technologies including fertilizers and pesticides create some problems in the soils and .environment (Mengel, 1990).

The rapid increase in the use of pesticides in agriculture has led to concern about its environmental effects. Agricultural development and human health are closely related to the use of pesticides. Many 
studies have shown that many of the insecticides directly inhibit the nitrification by soil bacteria, cause the decay soil organism and consequently disrupt the physical ecosystem. Moreover, pesticide has substantial negative effects on overall animal and human health as well as aquatic ecosystem. It is, therefore, important to have adequate knowledge on farmers' awareness on the effect of pesticides on environment.

\section{Material and method}

\section{Study Area}

An area was selected purposively as the locale of the study keeping issue of acquaintance of researcher with the farmers and their farming areas. Purposive sampling of the study area was done because of closeness with researcher's own area. The study area encompasses only one village (Kbaria kanda) under sadar upazila (sub-district) of Mymensingh district. The name of the village is Kbaria kanda. Approximate distance of the village from Muktagasa upazila is around 6 to $5 \mathrm{kms}$ north and from Mymensimgh town is around 14 to $15 \mathrm{kms}$ west.

\section{Sampling Design}

A list of farmers of the study area was prepared by the researcher herself with the help of Sub-Assistant Agricultural Officer (SAAO) of sadar upazila Agriculture Office. The list comprised a total of 302 farmers in the study area excluding the landless and marginal farmers. These farmers constitute the population of this study. To make a representative sample, 23 percent of the farmer was selected through random sampling technique. Thus, sixty nine (69) farmers were selected as sample.

\section{Instrument for Collection of Data}

In order to collect relevant information from the respondents, an interview schedule was used. The schedule was carefully designed keeping the objectives of the study in view. The schedule contained both open, closed and multiple choice questions. Most easy, simple, direct questions and different scales were used to obtain the information. Direct questions were used to obtain information, like age, year of schooling, household size, farm size and annual family income. Scales were used to measure media exposure and organizational participation of the respondents.

\section{Collections of Data}

Data were collected personally by the researcher herself from the sample by using interview schedule prepared in advance. The researcher realized that the collected data would be of no value if they are not valid. Whenever any respondent faced difficulty in understanding a particular question, the researcher took care to explain the same clearly. No serious problem was faced by the researcher in collecting the data. Excellent co-operation was extended by the respondents and other concerned at the time of data collection. Data were collected by the researcher herself from November 01 to 15, 2012.

\section{Analysis of data}

All the ends of data collection, data were compiled, tabulated and analyzed. Data were analysis by Mstate-C, Statistical package for Social Services (SPSS) and MS excel software.

\section{Results and Discussion}

\section{Selected Characteristics of the Farmers}

The findings of the selected characteristics of farmers namely, age, year of schooling, household size, farm size, annual family income, organizational participation, media exposure and knowledge on use pesticides agro-chemicals.

\section{Age}

The observed age of the farmers ranged from 25 to 70 years. The mean age was 45.78 years with standard deviation of 12.63. The farmers are classified into three categories and distribution of the respondents is shown in Table 1.

Table 1. Distribution of respondents by their age scores

\begin{tabular}{|c|c|c|c|c|}
\hline \multirow[t]{2}{*}{ Categories (years) } & \multicolumn{2}{|c|}{ Farmers } & \multirow[t]{2}{*}{ Mean } & \multirow[t]{2}{*}{ Sd. dev. } \\
\hline & Frequency & Percent & & \\
\hline Young $(<35)$ & 21 & 30.4 & & \\
\hline Middle-aged (36-50) & 29 & 42.0 & 45.78 & 12.63 \\
\hline Old $(>50)$ & 19 & 27.6 & & \\
\hline Total & 69 & 100.0 & & \\
\hline
\end{tabular}




\section{Years of schooling}

The year of schooling of the farmers ranged from 0 to 12 and the mean was 4.94 with standard deviation of 3.86. On the basis of scores obtained, the respondents were grouped according to national standard of classification. The categories and distribution of the respondents with their number, percent, mean and standard deviation are shown in Table 2.

Table 2. Distribution of respondents by their years of schooling scores

\begin{tabular}{|l|l|l|l|c|}
\hline Categories (years) & Farmers & \multirow{2}{*}{ Mean } & Sd. dev. \\
\cline { 2 - 3 } & Frequency & Percent & & \\
\hline Mass education & 17 & 24.6 & & \\
Primary (1-5) & 27 & 39.1 & \multirow{2}{*}{4.94} & 3.86 \\
Secondary (6-10) & 21 & 30.5 & & \\
Higher secondary (11-12) & 4 & 5.8 & & \\
\hline Total & 69 & 100.0 & & \\
\hline
\end{tabular}

Among 39.1 percent had primary, 30.5 percent had secondary level of education and 5.8 percent had higher secondary level of education. The majority of the farmers were found literate (from primary level to above secondary level).

\section{Household size}

The number of family members of the respondents ranged from 2 to 9 and the mean was 4.69 with standard deviation of 1.30. Based on the family size score, the respondents were classified into three categories. The categories and distribution of the respondents with their number, percent, mean and standard deviation are furnished in Table 3.

Table 3. Distribution of respondents by their household size scores

\begin{tabular}{|l|l|l|l|l|}
\hline \multirow{2}{*}{ Categories (no.) } & Farmers & \multirow{2}{*}{ Mean } & Sd. dev. \\
\cline { 2 - 3 } & Frequency & Percent & & \\
\hline Small (2-4) & 9 & 13.0 & \multirow{2}{*}{4.69} & \\
Medium (5-6) & 47 & 68.2 & & \\
Large (>7) & 13 & 18.8 & & \\
\hline Total & 69 & 100.0 & & \\
\hline
\end{tabular}

Data contained in Table 3 show that the highest proportion 68.2 percent of the respondents had medium family size as compared to 18.8 percent large and 13 percent small family size. The average family size of 4.69 of the respondents is lower than that of the national average of 4.9 (BBS, 2003).

\section{Farm size}

The farm size of the farmers in the study area varied from 0.20 to 4.20 hectares. The average farm size was 0.65 with standard deviation 0.77 . Based on their farm size scores, the farmers were classified into three categories and shown in Table 4 with number, percent, mean and standard deviation. Data computed in the Table 4 show that the highest proportion (84.1 percent) of the respondents had small farm as compared to 10.1 percent medium farm and 5.8 percent of the respondents fell in large farm category. Only 5.8 percent of the farmers had big farm. Thus, almost all the farmers possessed medium and small farm.

Table 4.Distribution of respondents by their farm size scores

\begin{tabular}{|l|l|l|l|l|}
\hline Categories (ha) & Farmers & Mean & \multirow{2}{*}{ Sd. dev. } \\
\cline { 2 - 3 } & Frequency & Percent & & \\
\hline Small (0.2-1.0) & 58 & 84.1 & \multirow{2}{*}{0.77} \\
Medium (>1.0-3.0) & 7 & 10.1 & & \\
Large (>3) & 4 & 5.8 & & \\
\hline Total & 69 & 100.0 & & \\
\hline
\end{tabular}




\section{Annual family income}

Annual family income of the respondent was measured in 'thousand Taka' per year. It was ranged from 15 to 550 with an average of 102.86 and standard deviation of 97.64. The distribution of the farmers in different categories on the basis of their annual income has been shown in Table 4.5 with number, percent, mean and standard deviation.

Table 5. Distribution of respondents by their annual family income scores

\begin{tabular}{|l|l|l|l|l|}
\hline Categories (Taka '000') & \multicolumn{2}{|c|}{ Farmers } & Mean & \multirow{2}{*}{ Sd. dev. } \\
\cline { 2 - 3 } & Frequency & \multicolumn{1}{|c|}{ Percent } & & \\
\hline Low ( $\leq 48)$ & 25 & 36.3 & \multirow{2}{*}{102.86} & 97.64 \\
Medium (>48-72) & 11 & 15.9 & & \\
High $(>72)$ & 33 & 47.8 & & \\
\hline Total & 69 & 100.0 & & \\
\hline
\end{tabular}

From Table 5 it is observed that the highest proportion 47.8 percent of the respondents had high income while 36.3 percent, 15.9 percent had low and medium income respectively. Since the greater proportion (52.2 percent) of the farmers had low to medium annual family income, it is logical to assume that they might have medium access to modern high cost technologies.

\section{Organizational participation}

The organizational participation scores of the respondents ranged from 0 to12, the mean and standard deviation were 1.63 and 3.11respectively. The respondents were classified into three categories. The categories and distribution of the respondents are shown in Table 4.6with their number, percent, mean and standard deviation.

Table 6. Distribution of respondents by their organizational participation scores

\begin{tabular}{|l|l|l|l|l|}
\hline Categories (score) & Farmers & \multirow{2}{*}{ Mean } & Sd. dev. \\
\cline { 2 - 5 } & Frequency & Percent & & \\
\hline No participation (0) & 50 & 72.5 & 1.63 & 3.11 \\
Less participation (1-11) & 17 & 24.6 & & \\
Medium participation $(>11)$ & 2 & 2.9 & & \\
\hline Total & 69 & 100.0 & & \\
\hline
\end{tabular}

Analysis of data contained in Table 4.6 indicate that the highest proportion (72.5 percent) of the respondents fell in the no participation category while 24.6 percent and 2.9 percent respondents fell in less and medium organizational participation category respectively.

\section{Media exposure}

The media exposure of the respondents in the study area ranged from 4 to 30 and the mean was 14.40 with standard deviation of 5.91. The distribution of the respondents in different categories on the basis of their media exposure has been shown in Table 4.7 with number, percent, mean and standard deviation.

Table 7. Distribution of respondents by their media exposure scores

\begin{tabular}{|l|c|l|l|l|}
\hline \multirow{2}{*}{ Categories (score) } & \multicolumn{2}{|c|}{ Farmers } & \multirow{2}{*}{ Mean } & \multirow{2}{*}{ Sd. dev. } \\
\cline { 2 - 4 } & Frequency & Percent & & \\
\hline Low (1-14) & 6 & 8.7 & & 5.91 \\
Medium (15-28) & 31 & 44.9 & 14.40 & \\
High (29-42) & 32 & 46.4 & & \\
\hline Total & 69 & 100.0 & & \\
\hline
\end{tabular}

Data contained in Table 7 show that the highest proportion (46.4 percent) of the respondents had high media exposure as compared to medium 44.9 percent and 8.7 percent low media exposure. Media exposure is important for receiving up to date farm information. 
Media exposure is important for receiving up to date farm information.

\section{Knowledge on the use of agro-chemicals}

Knowledge on the use of agro-chemicals of the respondents ranged from 15 to 32 and the mean was
23.08 with standard deviation of 3.92. The distributions of the respondents in different categories on the basis of their knowledge on the use of agrochemicals have been shown in Table 8 with number, percent, mean and standard deviation.

Table 8. Distribution of respondents by their knowledge scores

\begin{tabular}{|l|l|l|l|c|}
\hline \multirow{2}{*}{ Categories (score) } & \multicolumn{2}{|c|}{ Farmers } & \multirow{2}{*}{ Mean } & \multirow{2}{*}{ Sd. dev. } \\
\cline { 2 - 3 } & Frequency & Percent & & \\
\hline Less ( $\leq 11)$ & 0 & 0 & \multirow{2}{*}{23.08} & 3.92 \\
Moderate (12-23) & 51 & 73.9 & \\
High (24-34) & 18 & 26.1 & & \\
\hline Total & 69 & 100.0 & & \\
\hline
\end{tabular}

Analysis of data contained in Table 8 indicate that the highest proportion (73.9 percent) of the respondents fell in the moderate knowledge category while none fell in less knowledge and 26.1 percent in the high knowledge category respectively. The finding leads to assume that the farmers might have a good perception on environmental hazard which lead them to learn safe use of agro-chemicals.

\section{Perception on Environmental Degradation}

Perception on environmental degradation of the respondents ranged from 26 to 40, the mean and standard deviation were 35.91 and 2.18 respectively. The respondents were classified into three categories. The categories and distribution of the respondents are shown in Table 9 with their number, percent, mean and standard deviation.

Table 9. Distribution of respondents by their perception scores

\begin{tabular}{|l|l|l|l|c|}
\hline Categories (score) & \multicolumn{2}{|l|}{ Farmers } & \multirow{2}{*}{ Mean } & \multirow{2}{*}{ Sd. dev. } \\
\cline { 2 - 3 } & Frequency & Percent & & \\
\hline Less favorable (1-13) & 0 & 0 & & \multirow{2}{*}{35.91} \\
Moderately favourable (14-26) & 1 & 1.4 & \\
Favourable (27-40) & 68 & 98.6 & & \\
\hline Total & 69 & 100.0 & & \\
\hline
\end{tabular}

Analysis of data contained in Table 9 indicate that the majority 98.6 percent of the respondents had favourable perception compared to 1.4 percent of them had moderate and 0 percent less favorable perception regarding environmental degradation due to use of pesticides. Although, most of the respondents of the study area were either illiterate or had primary level education, their observation and may be high experience gave them such high perception on environmental degradation. Thus, their farming experience, observations, etc, may be the reasons for developing favourable perception on environmental degradation resulted from the use of pesticides.

\section{Relationships between Independent and Dependent Variables}

This section deals with the findings exploring relationships between the selected independent variables and the selected dependent variable of the study. The selected independent variables included age, years of schooling, household size, farm size, annual family income, organizational participation, media exposure and knowledge on the use of agrochemicals. The dependent variable was perception on the environmental degradation due to use of pesticides. The results of the test of co-efficient of correlation between the independent and dependent variables have been shown in Table 10 . 
Table 10. Correlation between independent and dependent variables

\begin{tabular}{|l|l|l|}
\hline Dependent variable & Independent variables & Computed 'r' values \\
\hline \multirow{4}{*}{\begin{tabular}{l} 
Perception on the $\begin{array}{c}\text { onvironmental degradation } \\
\text { due to use of pesticides }\end{array}$ \\
\cline { 2 - 3 }
\end{tabular}} & Age & 0.180 \\
\cline { 2 - 3 } & Hours of schooling & $0.290^{*}$ \\
\cline { 2 - 3 } & Farm size & 0.206 \\
\cline { 2 - 3 } & Annual family income & $0.348^{* *}$ \\
\hline & Organizational participation & $0.444^{* *}$ \\
\hline & $\begin{array}{l}\text { Kedia exposure } \\
\text { chemicals on the use of agro- }\end{array}$ & 0.174 \\
\hline
\end{tabular}

*Significant at 5 percent level of probability, ** Significant at 1 percent level of probability

\section{Conclusion}

Environmental degradation has caused great concern both nationally and internationally. Agriculture and environment interact in such a way that agricultural growth depends on the proper functioning of the environment process, the same way that environmental soundness depends upon agriculture. From this study we found about three-fourths (72.4 percent) of the respondents were young to middle age categories in the study area. Years of schooling and media exposure with information sources of the farmers had positive significant relationships with their perception on environmental degradation. Education has an important role for gaining knowledge and creating positive attitude. So, it may be concluded that educational levels of the respondents can be increased perception on environmental degradation. Annual family income and farm size had significant positive relationships with perception of environmental degradation. Therefore, if proper extension services are provided reflecting low-cost, small-scale, ecologically sound agricultural technologies, it will be popularized among them which in turn will promote farmers perceptions regarding environmental issues. Knowledge on the use of agro-chemicals is very important for environmentally safe crop production as well as for human health. However, knowledge on the use of agro-chemicals had significant relationship with their perception of environmental degradation. This means that the better knowledge on the use of agro-chemicals by the respondents the favorable perception of environmental degradation. This will ultimately help in reducing environmental degradation. The major proportion (98.6 percent) of the farmers had favorable perception of environmental degradation.

\section{References}

Conway, G. R. 1990. Agro-ecosystem In: Jones, J.G.W. and P.R. Street (eds.). Systems Theory Applied to Agriculture and the Food Chain. London: Elsevier Applied Science, pp. 205-233.

Hossain, S. M. A.; Salam, M. U and Alam, A. B. M. M. 1994. Scenario of Farm Environment of Bangladesh and Methodology for Quality Assessment. In: Proc. Workshop on 'Environmental issues.' GTI Pub. No. 99. Bangladesh, Mymensingh, Bangladesh Agricultural University: Graduate Training Institute.

Mengel, K. 1990. Impacts of intensive plant nutrient management of corn production and environment.101 congress international soil science Society, Kyoto, Japan, August 1218, Plenary Paper: 42-50.

Sarkar, T. M. 1993. Fisheries resources on the brink of danger. The Bangladesh Observer, 24 May 93: 8.

Sattar, M. A. 1994. Impacts of Agro-che micals. In: Ali, M. H. ed. Proceeding of Workshop on Environmental Issues. Pp.5-23. Graduate Training Institute, Bangladesh Agricultural University, Mymensingh (Pub. No. 99). 